\title{
Historical Connections of Sexism on the Matatu
}

\section{Jasmine Vallve}

Joanna K. Rozpedowski is a Doctoral Candidate in the Department of Government and International Relations at the University of South Florida, a Visiting Doctoral Student in the Department of Politics and International Relations at the University of Oxford, and the 2013-2014 US-UK Postgraduate Fulbright Scholar at the University of Liverpool School of Law. Her research interests include Cosmopolitanism, International Human Rights Law, European Union Institutions and Citizenship, Political Theory and Philosophy.

\begin{abstract}
This paper considers why the transportation sector, the matatu sector, in Nairobi is hostile towards women. It argues that the pressures of the sector have created an alienated environment for the workers which as a result projects misogyny. This paper first explains the rise of the informal economy in Nairobi and the pressures it creates. It then identifies the daily life of a worker and the demographics of the employees. It also explains how matatu workers are exploited and how this creates an alienated environment, projects sexism, and what the implications for this are.
\end{abstract}

Keywords: Exploitative labour, informal economy, matatu, misogyny, Nairobi, transportation. 


\section{Introduction}

Matatus are the main form of transportation in Nairobi and an urban phenomenon due to the way both the workers and passengers on the matatu can project norms, such as sexism. My research question asks, why is the matatu sector hostile towards women and what are the gender implications of this? Matatus are minivans that have been a source of transportation for Nairobi residents since colonialism. Under colonialism they were illegal, yet operators still would provide service for residents for three cents, which is where the name originates (matatu means three in Swahili) (Rasmussen 2012, 461). These types of vehicles are a low-income country phenomenon and can be found whenever there is a public need for transportation that the state is unable to provide, such as throughout sub-Saharan Africa (Mutongi 2006, 550). In this paper I will show that due to the intense pressures of the industry, matatu workers are aggressive because of alienation, which projects misogyny ${ }^{69}$. Mostly young males work in the matatu sector; many of which come from marginalized backgrounds. The workers are alienated in terms of how they do not have a control to the means of their labour, as they are placed in a highly exploitative position where the owners of production can demand unjust things. I will first explain through the literature how the informal economy has emerged and why it has created societal pressures for urban survival and how the matatu sector fits into this. Then, I will describe the daily life of a matatu worker in order to understand the relationship between the workers and the industry itself. Next, I will explain how matatu workers are exploited and how this creates an alienated environment. Then I will use the literature to show how the combination of these factors creates a misogynistic space and what the implications of this are. This social phenomenon is worth examining because there is a rise in informal sectors throughout sub-Saharan Africa due to the pressures of liberalization. Despite the research examining the economic consequences of informal employment there is very little research on the sociological impacts, especially relating to transportation. This should be further examined, as there are many unintended consequences of informal spaces. As these spaces grow, they will continue to alter social dynamics, specifically as it pertains to gender dynamics.

\section{Informal Economies Normalized}

The informal economy can be understood as a sphere of self-employment that has low-entry qualifications and small-scale workforces (see Myers \& Murray 2010, Keith Hart 1973). It is a vague term that characterizes one of the most common sources of urban employment in African cities, which consists of unskilled labour with a high turnover rate (Ibid). Informal employment is also based on a self-employment enterprise, which means that the workers have to mobilize their own resources. It is not just the urban poor who participate in the informal economy. The informal economy is unregulated and often extra-legal both in the treatment of workers and the

\footnotetext{
${ }^{69}$ The workers are alienated in terms of how they do not have a control to the means of their labour, as they are placed in a highly exploitative position where the owners of production can demand unjust things. My understanding of misogyny is defined as the hatred or dislike of women or girls. It can be manifested through sexual discrimination, denigration of women, violence against women, and the sexual objectification of women. This paper does not assume that all matatu workers are misogynists, but rather are a part of a work culture that is a catalyst for that sort of behaviour.
} 
activities it entails. Some common informal markets are street vending, basic service provision, and transportation. The informal economy is societally driven with minimal state presence. It is estimated that in the future the informal economy will account for $90 \%$ of urban jobs in lowincome countries (Sommers 2010, 322).

The growth of the informal economy emerged out of the patterns of mass urbanization in African cities without development over the past 50 years (Myers \& Murray 2010). Urbanization within the Global South, in general, is occurring at higher rates than industrialized countries, which has decreased the possibility for residents to find opportunities for formal work. This is due to the lack of infrastructure in transportation, sanitation, housing, and formal employment. It is also because of a lack of economic growth that typically prepares cities for a wave of population growth such as creating formal employment. This also occurred during a period of neo-liberalization as a capitalist order became globalized, which was spread through the introduction of Structural Adjustment Programs (SAPs) in many African countries (Hansen and Vaa 2004, 11). Under these programs states were expected to cut back on public expenditures, increase trade liberalization, deregulate the market, and privatize municipal enterprises (Myers \& Murray 5). These events eliminated the formal sector from urban spaces; as industrial jobs lack capital so there was labour market depletion, which resulted in an increase in unemployment and prices (Ibid). SAPs effectively drew the state out of service provision and the creation of formal employment. Society was expected to create jobs, housing, and social services, which became difficult, as these things at market value were only available to those who could afford it. This set the stage for competitive environments within the city, which was only exacerbated by the scarcity that emerged as a result of the lack of infrastructure and planning for the wave of urbanization. The combination of mass urbanization at a time of global neoliberal economic policies has weakened the ability for a formal economy to thrive in African cities. It has affected the order of economic activity and networks, as the state has not been able to provide for citizens, thus causing increases in poverty and social inequality (Hansen and Vaa 2004, 12). This has left youth to face the effects of poverty, unemployment, and illiteracy (Kilonzo 2012, 230).

Despite the fact the state was supposed to become laissez-faire under the SAPs, it was also compliant in other respects, which enabled the growth of the informal economy. By maintaining strategic business-political relationships, the state could benefit from the privatization of capital. By reducing the presence of capital in the public sector and allowing private capital to grow, formal employment continued to become scarce, which contributed to the growth of informal employment (Meagher 1995, 264). When the state is unable to provide public services citizens have to resort to private hierarchical linkages (Rasmussen 2012, 416). A pattern emerges when people begin to use informal networks to find service provision such as access to water and sanitation, as well as housing, which is dispersed in unregulated ways in the city by different groups. This is all in a manner that is untouched by the state. The state is tacitly enabling the development of informality by not creating an environment where formal employment can thrive. This compliance is a deliberate policy that is dismantling the institution of reproducing labour, which is left under control of elites who control informal markets (Meagher 1995, 279). The growth of the informal economy is not an act of liberation by the public; it is actually only possible due to the neglect of the state. With the pressures of neoliberalism, both the state and elite groups have created a system that voids each party of responsibility, while still experiencing 
economic gains. As the state has lost capacity to meet its responsibility to provide services to citizens, urban poverty has continued to spread (Sommers 319).

The matatu sector has always been private in Kenya, despite continuous attempts of the state to regulate it. President Jomo Kenyatta saw this sector as crucial to the livelihoods of citizens, so in 1973 he decided to lift all regulations surrounding transportation so that the owners could participate in a liberalized market (Mutongi 2006, 550). The matatu sector is the largest indigenous economic enterprise invented in Kenya. The use of matatus in Kenya has grown through patterns of urbanization and neoliberalism, given that the government has not attempted to takeover the sector in the long-term. The barriers to entry for the middle class owners were heightened with minimal legislation in 1984, The Traffic Amendment Act, which created regulative matatu inspections annually (Mutongi 2006, 555). This made operations more expensive, as the vehicles had to be maintained, which was a cost that not all middle-class entrepreneurs could reach given the economic restrictions of liberalization. This created a hierarchical structure in the sector, with ownership consisting of $20 \%$ of the sector, as it was more difficult for someone to own a matatu with the unintended costs of repairs. There were also hikes in insurance, as the insurance companies knew this was a mandatory factor of matatu ownership. Matatu ownership became monopolized, to the extent that only upper-class elites could access this market. There were no longer middle-class owners with one vehicle operating in the sector, as they could not keep up with the rising costs. This law opened up space for "saccos", which were registered businesses with multiple vehicles, run by elites. They solidified their monopoly by forming route-based cartels (Rasmussen 2012, 419 and Katumanga 2006, 508). Each sacco would have their own section of the city to make profits, which was based on the agreement that one group would not take over another group's area. This division of rents was a way to manage what groups could access the market.

This law is an example of how the government still seeks to impose fees and control in the informal economy where possible, as intervention in the sector fundamentally changed the barriers to entry (Meagher 1995, 262). Furthermore, in sectors that can generate large amounts of money, the state will attempt to "regulate" it by imposing arbitrary fines in an inconsistent manner. The transportation industry is an example of this, as a single matatu can generate large sums of money in a day, which attracts attention from politicians and law enforcement (Rasmussen 2012, 418). That being said, it was not uncommon to find roadblocks set up by traffic police after this law was created. Many officers began to demand bribes from matatu operators under the threat of inspecting the vehicle (Mutongi 2006, 555). This has become so common that it is one of the many anticipated fees that a driver will expect to pay regularly. In some instances where the matatu workers do not bribe the police, they will be arrested or have their sacco suspended from routes (wa Mungai and Samper 2006, 60).

The informal sector also has negative effects on livelihoods, as it operates on a patronage network, with the workers getting paid a fraction of the money being earned despite intensive time and effort put into the labour (Myers \& Murray 2007, 6). Matatus are known for their dangerous driving and unruly treatment of passengers (wa Mungai and Samper 2006, 57). The livelihoods of employees are often illegal, given the state of labour wages and hours, respective to the owner's demands (Sommers 2010, 322). Many urban residents who seek to generate additional income will participate and facilitate this type of labour, such as the restricted 
ownership of matatus to a small group of elites. The patronage strategy is the main form of regulation, because it forces workers to remain loyal. This system helps maintain the social network that comprises of these workers, and limit turnover when possible. Although it appears to be resourceful, many informal workers have turned to this market as a survival strategy. The informal workers comprise approximately $80 \%$ of the sector as a whole, with the other $20 \%$ being the owners of informal production (Meagher 1995, 268). The increases of unemployment and intense livelihood pressures caused a flood of entry into the sphere, which has created mass fragmentation among the young workers (Meagher 2011, 56). This is due to the increased competition, which causes individuals to develop tensions among class, age, and gender. There are still barriers to entry due to the competitive nature of the sector and the tendency for elites to grant positions based on patronage relationships. Patronage structures are an informal practice where an elite will grant favors or positions to those who will help advance their interests. This is a rigid, top-down structure that has a hierarchical nature.

One of the cartels that came into control of many of the matatu routes was the Mungiki, a youth vigilante group that emerged in Nairobi in the 1980s (Kilonzo 2012, 233, Rasmussen 2012.) Mungiki took control over the sector after establishing its prominence as an urban militia that employed marginalized youth from slums through patronage strategies (Ibid). Using the matatu sector as a springboard, the group moved into other informal areas such as garbage collection, settlements, and racketeering for security as it grew in prominence (Ibid). Mungiki regularly extort money from matatu operators, at a rate of approximately $200 \mathrm{KSH}$ (\$2.50 USD) per trip. In 2007 the matatu sector began to complain about this extortion, which resulted in a wave of killings of matatu workers in various slum neighborhoods (Ibid, 236). Mungiki nets 90 million $\mathrm{KSH}$ (1.3 million USD) a day, a majority of the profits coming from extortion (Ibid). Despite the coercive nature of the group, it also provides public services to slum residents (at a cost) such as security, power installation, and toilet cleaning (Ibid, 237, Rasmussen 2012). Mungiki forcefully recruit marginalized youth, which explains their ability to extent into various communities within Nairobi (Ibid). Mungiki are an example how the informalization of society leads way to other powerful elite groups to grow in prominence. Its manifestation is one of the ways that disenfranchised youths have showed governments that they need to deal with youth issues and socio-economic challenges (Ibid 243, Rasmussen 2012, Sommers 2010).

The combination of patronage, a dense social network, and marginalized workers is what allows the informal economy to thrive. Those who control sectors will quickly exploit those who they know are most willing to participate in undesirable jobs to prove themselves, which often falls under young workers. Many of the citizens who have participated in mass urbanization are young men and women who come to cities to seek employment (Rasmussen 2012, 418). There are few economic opportunities in the formal and public sector, which cause youth to resort to the informal sector (Hansen and Vaa 2004, 13, and Meagher 1995, 265). This is challenging, as it may seem that the informal economy is opening up economic opportunity to marginalized groups, when the opposite has occurred. The intense pressures leave out any opportunity for apprenticeships, regulations, or collective organization (Meagher 2011, 58). This entrenches the patronage structure, and makes it increasingly difficult for young workers to voice their demands. The state is also a complicit bystander in that it is their failure to provide services that causes citizens to resort to informal strategies for survival. Despite their complicity, states often do not 
always have a choice in whether or not to participate in a global economy that may or may not allow them to thrive. In order to continue to receive assistance, they must meet these demands, considering that if they did not comply they could be in an even worse socio-economic situation. This predicament is paralleled in the matatu worker, as they too are forced to participate in this economic order.

\section{The Alienated Worker}

If one examines the daily life of a matatu worker, it is degrading due to the need to bribe and then push themselves onto both passengers and peers to meet quotas. This creates a reckless mentality that often results in many car accidents. This is an unfortunate combination considering there is little money to take home after all of this. Elite members of society are the owners of matatus who then will rent the vehicles out to employees. That matatu driver is supposed to pay for the rent of the vehicle daily to the owner, gas, and any parking fees. In addition they are expected to pay traffic police, often through bribery. The remaining money at the end will be divided between the driver and the tout, who is trying to get passengers on the bus. The average working day of a matatu driver and tout is approximately 18 hours (Mutongi 2006, 554). Workers are pushed by the owners to do anything in order to meet a daily quota (Ibid). As a result, safety laws are seldom abided by due to the need to make that minimum amount of money; customer service is often disregarded again due to the demands (Ibid, wa Mungai and Samper 2006). Preventable accidents are very common, as the drivers often speed and drive recklessly (Raynor and Mirzoev 2014, 344). The justification for dangerous driving is the fact that the owners push the drivers to make a minimum amount of money daily and the driver wants to make enough so that he has something left over for himself (wa Mungai and Samper 2006, Rasmussen 2012). Drivers are paid based on the amount of passengers they have, so the constant state of rushing as many passengers on is their primary concern. What is troubling is that a matatu worker may make more than they would at an entry-level administrative job, despite how hard they are to come by. (wa Mungai and Samper 2006, 557) A majority of employees within this sector are young marginalized lower-class males. They are economically vulnerable and so as a means of identity they project sexism to protect their idea of a positive identity. This pervasive culture has been integral to the growth of the sector and its exclusion of women. To work within a competitive atmosphere of the informal economy such as this, it requires aggressive behaviour, as there are no guarantees of retaining your employment despite the long hours and hard work (Ibid, Rasmussen 2012, 418). Matatu workers are underpaid in comparison to the money that they produce, which creates alienation due to the unrealistic expectations they must meet, given that they do not own their means of production. Furthermore, they are reduced in their mobility with little exit strategy (Salon 2010). For these workers, it is a matter of survival to make the bare minimum that the sector requires - this goes beyond the conception of a competitive environment. This competition occurs in a group setting, as there are many workers that are constantly interacting. The sector is often the only source of social survival for marginalized youth, whose only realistic opportunity is to one day become a matatu owner and continue the cycle (Rasmussen 2012, 418).

Informal work for youth has become exploitive due to the intense competition, which makes working spaces highly contested (Sommers 2010, 320). A worker is forced to meet the demands 
of the sector, as another person would be willing to take their position if they failed. Matatu owners have begun to seek employees as young as high school boys, given the deteriorating economy and the willingness of young boys to work in the sector (Mutongi 2006, 557). When many unemployed individuals are seeking the few available positions, it becomes easy to find replacements that are willing to work under dire conditions (Ibid, 554). The work that youth are engaged in often has small returns or is labour in return for bartered items or services, which is not nearly enough for a living wage in urban spaces (Sommers 2010, 323). This causes alienation because they are subjected to the demands of another person and are forced to partake in a relationship that is highly exploitative. The amount of work put in in comparison to the returns is uneven, and the labour itself is often indirect and takes form of scattered services. Most of this labour is temporary and requires people who are cunning and aggressive to be able to keep up with its demands (see Sommers 2010, Mutongi 2006). Youth have to be able to adapt to this behaviour in order to "make it" in the urban setting, which many are willing to do. It is the most feasible alternative in comparison to trying to find formal work or returning to rural homes, which also has minimal opportunities. In Nairobi, an informal worker is called a "hustler", based on his need to hustle for various jobs given the lack of consistent work available. This stage in between casual labour and unemployment is very common for urban youth.

In addition to being alienated from labour, youth are also increasingly alienated from society. Despite the fact that they make up a majority of urban populations, youth feel excluded due to the assumptions that they are violent and corrupted members of society (Sommers 2010, 324). On top of the pressures that come along with scarce employment, the stigma associated with it makes youth seem unfavorable in urban spaces. This dialogue that youth are dangerous to cities and should not occupy it is not uncommon (Sommers 2006, 2010). Youth are often treated as the scapegoats of urban issues, as they are often an already marginalized group (Katumanga $2006,507)$. This alienation at the societal level impacts how youth interact with other members of society. As this perception grows within youth identity, it becomes easier for one to be hostile. If youth already feel like they are unwanted on top of all of the other pressures they have to face, apathetic behaviour is a quick coping mechanism. Matatu workers are forced to behave aggressively due to external pressures, but when this exists as well as the negative stereotypes associated with youth in general it creates an environment where the worker never feels wanted.

At its inception, the public views towards matatu workers were positive. However, this changed in the $80 \mathrm{~s}$, as wealthy men began to take advantage of the lack of regulation in the sector and transformed it, with a $30 \%$ increase in matatus on the road and the rising prominence of cartels (Mutongi 2006, 554, wa Mungai and Samper 2006, 60, Rasmussen 2012). This resulted in an increase in competition, which is why matatu workers became increasingly aggressive, thus ruining public perceptions. The sector still became one of the largest entrepreneurial sectors in Kenya, which drew in the interests of more elites and increased competition (Ibid). Matatu operators in Nairobi are now seen as thugs who exploit and mistreat passengers, as well as participating in gang-like violence (Mutongi 2006, 549 wa Mungai and Samper 2006, 57, Rasmussen 2012). Some of the common traits of matatu workers include misogynistic language, loud music, overcrowding, speeding, and the rough handling of passengers (Ibid). 


\section{Implications of Misogyny}

Traditional gender roles in urban spaces are a contributing factor to the misogyny seen in matatus. Although mass rural migration has occurred for youth, many still believe that males should dominate the public sphere, which can create dangerous trajectories (Sommers 2010, 324). This explains the overall male presence in the matatu industry, as it is not seen as a place where a woman should thrive. Another role is the notion that men are taught how to exercise authority while women are taught to be submissive. This dichotomy creates space for men to express themselves without repercussions (wa Mungai and Samper 2006, 58). They are socialized in a manner where it is accepted to be authoritative towards others and express prejudiced views because just being a man acceptably habituates it. Furthermore, this is an expected behaviour, which has consequences for those who do not conform to this standard. Under group settings, males are pressured to adhere to these norms. To not act in the way that other authoritative males are often leads to that person being criticized for not being masculine enough. It can become escalated when combined with the pressures of the sector, which provides an understanding behind the tendencies for the workers to project aggressive behaviour. Although the urban space is understood as a space of modernity, these rigid gender roles contribute to the perceptions of how women and men should act.

Urban male youth are particularly vulnerable to the harsh societal expectations of masculinity that exist in comparison to the minimal economic opportunities that exist (Barker 2005, 13). Society imposes particular behaviours on males, and when males cannot fit into that definition they are often victimized. On top of male authority being a gender rigid role, another role is the expectation of the male as a breadwinner. When a male reaches manhood, there is an expectation that they will have adequate employment (Ibid, Sommers 2010). With all of the structural obstacles mentioned, it is difficult for youth to be able to meet these milestones in their life. When a man cannot provide for a family and progress societally, his manhood is questioned (Ibid). Hardships are a setting that makes one question male identity. When that is challenged, males struggle to handle those pressures (Sommers 2010, 324). When males feel emasculated, they can often resort to aggressive behaviour (Ibid). Another tendency is to point out gender differences (for example a male nurse will say they aren't interested in the nurturing aspects of a job but rather the science and technical aspects) in order to maintain their manhood. If a male's public space feels threatened they can react through misogynistic practices. Aggression in the matatu industry can be understood as an expression of manhood, as labour is a central component to identity (Barker 2005, 21). Without employment, males cannot adequately express their identity, which resorts to demeaning behaviour in order to reclaim that identity (Ibid).

When females are excluded from an occupational space it can negatively affect their social status. It can also result in normalizing how men conceive of how women should perform in an acceptable role and so it becomes customary to exclude them (Raynor and Mirzoev 2014, 316, Barker 2005). There is a perception that matatu work is not for females due to its aggressive work conditions. Both passengers and other matatu workers frequently harass the few female matatu workers that exist, calling them prostitutes among other forms of derogatory language (Mutongi 2006, 564). This line of thinking that suggests that women aren't suitable for certain forms of work shows that society has a learned tendency to believe how a male and female should stereotypically behave (Anker 1997, 316). This contributes to gender stereotypes, which 
has problems on both sides. For females, when their behaviour is normalized to fit a certain frame it becomes easy for males to demean them when they do not fit the standard. Like with the example of the male nurse, males are celebrated for taking on roles that would be conventionally female and build their identity on the masculine aspects of the profession. But when a female enters a male-oriented space, she is discredited and demeaned (Ibid). Although there is a male advantage, males still have the expectation to associate themselves with the masculine identity of their profession (Ibid). Jobs that are perceived as "masculine", such as the matatu industry, have a set of behavioral standards that the male is supposed to meet. This once again contributes to a man's masculinity to come into question when it does not meet certain standards, which can have demeaning effects. These stereotypical expectations make it hard for people to adopt individual identities, as they must adjust to societal gender constructs.

The misogyny that exists within the matatu space begins with the artwork or stickers on the matatus themselves. Some of the stickers read, "A woman is like a common maize cob for every man to chew," and "Men are like oxygen women cannot do without them" (Mutongi 2006, 560). Matatu workers defend these types of stickers by saying that the customers find them funny (Ibid). Whether or not this is the case, it is uncommon for a passenger to criticize the stickers, considering that they rely on the matatu for transportation, are aware of the aggressive tendencies of the workers, and might take amusement in them. This creates an environment where misogynistic language becomes tacitly permissible. The conformity of commuters enables this tendency, which makes it increasingly difficult for these deep-seeded views to change (wa Mungai and Samper 2006, 58). It leads to an excessively masculine culture, which becomes reinforced as the workers continue to face hardship. This type of projection of misogyny is also hard to fight, as the matatus are not under government control so they are not subject to any workplace codes or human rights violations.

The Kenya Demographic and Health Survey (KDHS) in 2009 indicated that approximately 45\% of women aged 15-59 have experienced either physical or sexual violence (KDHS Survey 2009). The Police Annual Crime Report showed an 8\% increase in rape, and 19\% increase in defilement (Ibid). In this report, 23\% had experienced rape, 13\% of which occurred in the past year (Otsola 2012). Whether it is a comment on a young woman's body, derogatory remarks or an insult, this more direct behaviour is common (Ibid, 565, Githinji 2008, 26). There have been frequent accounts of matatu workers sexually and physically assaulting female passengers as well (see wa Mungai and Samper 2006, Carotenuto 2012, 60, Guguyu 2014). Despite this, there have not been any surveys conducted to quantify the percentage of women who experience assault or harassment in the matatu space. This, in connection with the limited data on the statistics of gender violence in Kenya, could be due to the prevalence of socialization. Women in Kenya are socialized to accept, tolerate, rationalize, and to remain silent on these experiences (Otsola 2012). The most recent research suggests that there is a correlation between population density and gender violence (Ibid). This behavior contributes to, and is exacerbated by, the economic and socio-political discrimination that women face (Ibid). This has negative implications as the matatu industry has grown through population density and is in itself a gendered space that can create likely conditions for gender-based violence.

Objectification is one of the most prevalent forms of harassment/assault on matatus. Workers are confident enough to harass passengers, knowing that the other passengers are unlikely to 
challenge their actions. Whether this is due to fear of the workers or the possibility that the passengers agree with what is being said in the case of insults, it is another example of unwarranted misogynistic behaviour (Mutongi 2006, 566). The objectification of women in public settings has many consequences, including the normalization of these acts. By participating, male authority and female passivity is re-asserted. Derogatory language has the tendency to portray women as deviants given that social roles are biased against women (Githinji $2008,30)$. It publically reinforces the acceptability of male aggressiveness towards females.

In Nairobi, matatu workers recently stripped a woman naked for thinking that she was dressed inappropriately (Guguyu 2014). This resulted in charges laid against the workers, however it also resulted in additional cases of women being stripped by matatu workers for perceived inappropriate clothing as well as sexual assaults (Ibid). Public stripping is not a new act in Nairobi. Mungiki have stripped women who wore trousers and miniskirts, believing that women should return to indigenous beliefs and practices (Kilonzo 2012, 223). They are part of a bigger societal pressure for women to conform to various cultural norms. Public humiliation of females on matatus date back to the colonial period in Kenya, and points to a broader history of public violence being used to shape a morality of civic virtue and a gendered conduct (Carotenuto 2012, 9). In this sense, public corrective measures have become a part of urban culture in order to reflect the traditional expectations of female behavior. These events have sparked protests entitled "My Dress My Choice," and condemnation from the government, but this speaks to the type of attitudes that exist towards the role of male authority governing female lives. It also expresses a positive push back against those attitudes, which is arguably an attempt to reshape them. This is an extreme case of misogyny, where the workers felt they had the right to dictate how a female should present herself in society. Although there is a public call for retribution, these acts mirror a greater spread of sexism as a result of the masculinity that matatu workers project. These views could possibly reflect a societal view of gender appropriateness in Nairobi. The act of public harassment and shaming to reinforce male authority helps entrenches a dichotomous and hostile masculine identity. Public shaming may reaffirm this belief, as people do not correct the shaming and people are not learning what is and is not acceptable.

Many commuters acknowledge that matatu workers will never change due to the pressures they face and that is a price to pay in accepting their provision of transportation (Mutongi 2006, 561562). Some even argue that this aggressive behaviour reflects the aggressive and youthful qualities of Nairobi (Ibid, 563). Despite the concession, matatu workers acknowledge that they have to meet daily demands, which forces them to react to bad circumstances generated elsewhere (Ibid, Rasmussen 2012, Raynor and Mirzoev 2014). Furthermore, matatu workers are often the scapegoat for larger issues at hand despite the fact that they are trying to survive under intense circumstances that has resulted from government being unengaged (Mutongi 2006, 563). These pressures cause them to lash out and be aggressive as well as occasionally participate in illegal actions (Ibid, Rasmussen 2012, Raynor and Mirzoev 2014). The dangerousness and high instances of accidents, as well as overall behaviour can be attributed to the consistent demands from both passengers and owners. The acknowledgement of aggressive behaviour shows that the workers do not always act in this way, but the job is what reduces them to this (Ibid). What is interesting is that the workers are able to admit the connection between the pressures and their 
actions, however there is rarely a dialogue surrounding some of the reasons behind their tendency to be misogynistic.

One plausible reason for this is the fact that the industry has created such a masculine culture that is integral to the survival of a worker. The industry has supported fostered characteristics that are traditionally associated with males, and it has become integral to the survival of the worker. The workers themselves are able to acknowledge that they are projecting their frustrations on others, but are not self-critical as to why they are projecting certain ideals over others (Mutongi 2006, wa Mungai 2006). This is significant because vulnerable men tend to hang on to the one part of their identity that cannot be contested, their manhood. A worker may not be able to self-direct their work and may be heavily exploited in their workplace but can still characterize their work in a desirable way that is socially rewards along the lines of gender. By engaging in misogynistic dialogue, it tries to re-affirm male hierarchy, which can serve as a comforting reality. By virtue of participating in a manly work culture they are able to retain a positive identity, one that aligns acceptably with who they socially are supposed to be. This can have long term implications as gender stereotypes can be rigid, and can perpetuate gender inequality to further generations (Raynor and Mirzoev 2014, 316). Alternatively, it can promote the assertion of rigid, dichotomous gender stereotypes so that males can maintain positive identities. However it can also perpetuate gender inequalities unto further generations.

\section{Conclusion}

Young, male matatu workers are trying to survive in a highly competitive market that demands aggression and subjects them to highly exploitative, vulnerable labour. To maintain some positive outlook and they resort to highlighting and excluding certain gender features within their work, which results in an atmosphere that is very hostile to women. There is an intertwined relationship between the tendencies for males to project masculinity within their workspace and the lack of social rewards that comes from their labour. As a result of these inner-conflicts, they resort to sexist behaviours. This contributes to rigid societal gender roles, and makes it hard for both men and women to challenge them. This also has negative implications for gender roles within society. As this behaviour persists, it will remain difficult for women to challenge the sexist spaces they must exist in. The structural rigidities of the sector also make it difficult to conceive of how the workers can reclaim their identity in a way that is not derogatory to others and self-empowering in a holistic manner. If there is a correlation between population density and gender-based violence as Otsola (2012) poses, then a critical examination of gendered labor spaces is necessary, as Nairobi is a city that is rapidly urbanizing (thus increasing population density). The worker's identity is a large part of this struggle. The informal economy is not always a state of survival like the matatu industry is, but the intensity of struggle pushes worker's behaviours and identities. In a sense, bare necessity reduces people to this. By having to operate and survive in this highly competitive atmosphere, it becomes evident how this struggle creates space for misogynists. Although females are sparsely challenging the societal expectations forced upon them, they are outnumbered by a larger voice of misogyny in public spaces. In order to address this issue, one must first consider the structural reasons that are causing matatu workers to act this way in the first place. 


\section{References}

Anker, Richard. 1997. "Theories of occupational segregation by sex: an overview," International Labour Review 136: 315-330.

Barker, Gary. 2005. Dying to be men: youth, masculinity and social exclusion. London: Routledge.

Carotenuto, Matthew. 2012. "Repatriation in Colonial Kenya: African Institutions and Gendered Violence." The International Journal of African Historical Studies 45 (1): 9-IV.nai

Githinji, Peter. 2008. "Sexism and misrepresentation of women in Sheng," Journal of African Culture Studies 20: 15-32.

Guguyu, Otiato. Friday, November 28, 2014. "Kenyans posting stripping videos risk arrest" The Daily Nation. Accessible at WWW: http://www.nation.co.ke/news/Kenyans-posting-strippingvideos-risk-arrest/-/1056/2538274/-/3iys1q/-/index.html

Hansen, Karen and Vaa, Mariken. 2004. "Reconsidering Informality Perspectives from Urban Africa," Madrid: Grafilur Artes.

Katumanga, Musambayi. 2005. "A City under Siege: Banditry and Modes of Accumulation in Nairobi, Kenya," Review of African Political Economy, 106: 505-20.

Kenya Demographic and Health Survey, 2008-2009. Final Report: Nairobi, 2010.

Kilonzo, Susan. 2012. "The trajectories of survival of the Mungiki youth in Nairobi," 229-250 in Bourdillon, Michael and Sangare, Ali, Negotiating the liveliboods of children and youth in Africa's urban spaces Dakar: Codesria.

Murray, Martin and Myers, Garth. 2007. "Introduction: Situating Contemporary Cities in Africa," pp. 1-30 in Murray, Martin and Myers, Garth, ed. Cities in Contemporary Africa. New York: Palgrave Macmillan

Mutongi, Kenda Beatrice. 2006. "Thugs or Entrepreneurs? Perceptions of Matatu Operators in Nairobi 1970 to the Present," Africa: The Journal of the International African Institute 76 549-568.

Meagher, Kate. 1995. "Crisis, Informalization, and the Informal Economy Sector in Sub-Saharan Africa," Development and Change 26: 259-284.

Meagher, Kate. 2011. "Informal Economies and Urban Governance in Nigeria: Popular Power or Political Exclusion?" African Studies Review 54: 47-72.

Otsola, John. 2012. "Baseline Survey Report on Gender Based Violence in Kasarani, Nairobi Kenya" Women and Children's Wellness Centre Policy Paper.

Rasmussen, Jacob. 2012. "Outside the Law - Inside the System: Operating the Matatu Sector in Nairobi," Urban Forum 23 (4): 415-433 
Raynor, Nicholas and Mirzoev, Tolib. 2014. "Understanding road safety in Kenya: views of matatu drivers" International Health 6: 242-248.

Salon, Deborah and Gulyani, Sumila. 2010. "Mobility, Poverty, and Gender: Travel 'Choices' of Slum Residents in Nairobi, Kenya," Transport Reviews 30: 641-657.

Sommers, Marc. 2010. "Urban Youth in Africa," Environment and Development 22 (2): 317-332

Wa Mungai, Mbugwa and Samper, David. 2006. "No Mercy No Remorse, Personal Experience Narratives About Public Passenger Transport in Nairobi," Africa Today 52: 51-81. 